\title{
Genetics and the British insurance industry
}

\author{
E David Cook Green College, Oxford
}

\begin{abstract}
Genetics and genetic testing raise key issues for insurance and employment. Governmental and public concern galvanised the British insurance industry into developing a code of practice. The history of the development of the code, issues of genetic discrimination, access to medical information, consent and the dangers of withholding information and the impact on the equity of pooled risk are explored. Proactive steps by the Association of British Insurers suggest that moral reflection not legislation is the way forward.
\end{abstract}

(Fournal of Medical Ethics 1999;25:157-162)

Keywords: Ethics; genes; insurance; genetic screening; risk rating; consent; genetic testing; Association of British Insurers; $\mathrm{ABI}$ code of practice; government and public pressure

The response of the British insurance industry to the challenges of genetics provides an interesting case study in ethical and legal reflection on new medical technologies and their impact on society and its institutions.

\section{Background}

The first major ethical reflection on the Human Genome Project in the UK was the report of the Nuffield Council of Bioethics Working Party, Genetic Screening: Ethical Issues, in December 1993. ${ }^{1}$ In their chapter seven, insurance was examined. They held it was unlikely that genetic disorders which were already manifesting symptoms would create any new ethical dilemmas, but that as testing for late onset disorders became more widespread and as genetic screening increasingly identified individuals with a predisposition to develop certain diseases, new issues might arise. Genetic screening would benefit insurance companies by leading to the avoidance of the birth of affected children.

Insurance, the report argued, is based on the complementary principles of solidarity and equity: solidarity implying the sharing by the population as a whole or in groups of benefits and costs. Equity implies that the contribution of individuals should be in line with known levels of risk. There is a fundamental difference between the insurance industries in the UK and the US. Because of the provision of health care through the National Health Service, the market for private health insurance has not been extensive. Funding shortages, issues of resource allocation and waiting lists have all increased the take-up of health insurance and the role of private medicine. The American scene, deploring "socialised" medicine, has a full range of private health insurances for those who can afford it or work in settings where the employer meets the health insurance bill. The UK insurance scene is much more focused on house purchase, life insurance and assurance; and if people were effectively to be excluded from this, because of their genetic condition, there would be serious consequences for public policy and social security. After exploring the different perspectives at stake and stressing the difficulty in assessing genetic susceptibility, overcautiousness in the commercial assessment of risk derived from medical data and the possibility of abuses, the report concluded and recommended that British insurance companies should adhere to their current policy of not requiring any genetic tests as a prerequisite of obtaining insurance, that the government and the insurance industry discuss the future use of genetic data and that, pending the outcome of that discussion, there should be a temporary moratorium on the requirement to disclose genetic data, with two exceptions. Those were in cases where there was a known family history of genetic disease that could be established by the conventional questions about the proposers' families and that the moratorium should apply only to policies of moderate size.

\section{Governmental pressures}

The 1995 House of Commons Science and Technology Committee's report on Human Genetics stated: "In our view the ABI (Association of British Insurers) has reacted to these predictions [of genetic science having major implications for the insurance industry in a relatively short time] with undue complacency; it would, at least, be prudent 
to have contingency plans in place to ensure that changes were dealt with in an orderly manner". ${ }^{2}$ [Brackets my amplification.] Coupled with this was pressure from the Human Genetics Advisory Commission, which advises the government on the need for and shape of legislation.

The insurance companies were confronted with governmental pressure, negative press publicity and the need to win over public opinion and reduce the level of fear. There was also a clear concern that if the insurers did not put their own house in order then government would introduce more stringent laws, forcing restrictive policies on them. In paragraph 248, the House of Commons Science and Technology Committee Report recommended "that the insurance industry be allowed one year in which to propose a solution acceptable to Parliament, and that if it fails to do so a solution should be sought, by legislation if necessary". ${ }^{3}$ In light of the real pressure, the industry's concerns were not misplaced. The ABI produced a policy statement on genetics to allay public and political concerns. ${ }^{4}$ The statement stressed that forbidding insurers access to genetic information produces a situation in which people who have had tests which reveal them to be at high risk, can over-insure themselves, thus risking considerably higher premiums for everyone. The overwhelming view of the industry was that it was necessary for it to have all relevant medical information. The industry did not believe that making available the results of existing genetic tests would prejudice genetic development. The insurance companies did not currently request individuals to take genetic tests and this would remain the policy of the industry for the foreseeable future.

The policy statement sets out the responsibility of the insurance industry in terms of confidentiality, sensitivity and evidence-based decisions, the rating of risks, the seeking and use of genetic information, and the handling of genetic information. The ABI then put in place three key elements in its response to the various concerns. It appointed a genetic adviser, whose responsibilities included the provision of accurate and up-to-date information about genetic developments, including the impact of a particular test and its relevance. His advice would sit alongside information about the length and nature of any insurance policy to be purchased.

A genetics committee was set up to review all arrangements relating to genetics and insurance. This was comprised not only of insurers but also individuals from outside the industry with expertise in legal, ethical and social issues. This committee was to take the lead in drawing up and keeping up to date a code of practice for the insurance industry.

\section{The code of practice}

The code demands high standards in the insus ance industry's approach to genetic issues, estab? lishes a base for research into genetics and insuis ance and introduces a benchmark fo⿺ transparency in the underwriting process. provides a basis for monitoring practice and witt be reviewed as to its effect every two years.

The core principles are expressed as:

1. Insurers will not impede the progress genetic science.

2. Insurers will not discriminate unfairly againș individuals affected by, or with a family history of, a genetic condition.

3. Applicants will not be asked to undergo genetic test as a prerequisite for taking out insurance. There is no indication that scientife advances will necessitate any changes in thi principle. Should such advances come about ifo the future, any proposed change in practice wifi be subject to thorough and wide consultation

4. Details of genetic test results will not bs requested from a medical attendant withou the prior informed consent of the applicang Incomplete information may affect the unde? writing decision.

5. Genetic information relating to one fami member will not be linked or transferred applications for insurance made by another family member.

6. As with all medical evidence, insurers wi maintain high standards of confidentialit when handling genetic test results.

7. Unless genetic test results clearly indica increased risk, they will have no effect on the premium or on an insurer's decision to offer terms. Increased risk will not necessarily mean an increase in premium.

8. The underwriter will consult a medical praetitioner, normally the insurance companys chief medical officer, before reaching a final decision whether to increase premiums or decline an application, where a genetic tes result plays a part in the decision.

9. The reason for an increased premium or rejection of an application based on a genetic teg will be provided, on request, to the applicant medical adviser.

10. Insurers will not offer cheaper than normat (standard) premiums to individuals whó are perceived to have a good genetic profile.

11. Insurers will monitor their staff's complianc with the code, take action in the event of 
infringements and maintain an accessible complaints process.

12. Insurers will subscribe to an independent disputes resolution service.

These core principles were set in a double context. Medical science can predict accurately that those carrying single gene disorders, with a dominant pattern of inheritance, such as Huntington's disease, will develop the disease. The other part of the genetic context is the identification of an increased or decreased predisposition to certain diseases by genetics. The doubtful and as yet not fully reliable nature of such predispositions was noted. Recognising public concern about possible discrimination against specific individuals there was an equal concern that the principles and laws underlying insurance practice should not be undermined. At the time the code of practice was being prepared the ABI view was: "The principle of equity means that if individuals bring extra risk to the insured pool, they bear a proportionate, additional cost, rather than pass it on to other policyholders. Insurers fear too that individuals will break the legal contract of insurance by depriving the insurer of relevant information which, if exploited, would lead to the policyholder receiving a payout to which $\mathrm{s} / \mathrm{he}$ is not properly entitled. The costs of this action would be borne unfairly by other policyholders and, if taken to extremes, could lead to the company's failure". Taken from unpublished ABI code of practice preliminary papers.

The rest of the code sets out the legal position and the ethical background. It argues for continuing under the present legal framework, especially the Access to Health Records Act (1990), the Data Protection Act (1984) and the Disability Discrimination Act (1995). In ethical terms, the code distinguishes between the different principles it sees involved in health care provision based on commercial practice, and that funded from taxes. The former is based on mutuality and the latter on solidarity. Despite this difference, the code suggests that the same ethical tests are relevant to insurance and genetics and these include beneficence, non-maleficence, autonomy, equity, utility and confidentiality. There is a call for multidisciplinary discussions to ensure that a balance between the mutuality of private contracts and the solidarity of covering all essential health care needs for all UK citizens, is achieved.

The code then sets out what it considers to be the insurer's, the applicant's, the chief medical officer's and the genetic adviser's responsibilities. The key elements for insurers are that genetic test results are not used retrospectively to reassess existing cover, unless the applicant withheld relevant information, that applicants will not be asked to take a genetic test and that genetic test results will not be used as the basis for offering preferential premiums below the standard rate. The applicant is under no obligation to ascertain medical information currently unknown to him or her; to consent to disclosure of genetic information to third parties other than for reinsurance purposes, and not to undergo genetic testing for insurance purposes.

The chief medical officer and the genetics adviser have the responsibility for ensuring that insurance companies and members of the ABI are appropriately informed and act properly. The document then sets up an appeal process, allowing some redress for those who feel that the code has been breached and that they have been discriminated against on grounds of genetic information. ${ }^{5}$

\section{Critical reflection}

Moral philosophy tends to be reactive to new medical and moral dilemmas rather than proactive. In the area of genetics we seem to have an opportunity to be proactive by setting in place frameworks for the exercise and regulation of genetic science and its implications. Nowhere is this more important than in the areas of employment and insurance. We have a pretty good idea what genetics will enable us to do in terms of predicting the likely onset of diseases, how to test for such predispositions and disease and what kinds of treatment options may be in store. It is also relatively straightforward to construct the likely effects and dangers of the application of genetic technologies in the realms of medicine, society, employment and insurance.

Genetics is part of a wider set of issues covering not only insurance and employment, but also medical advances and the serious implications of both genetic and medical advances for individuals and families in terms of testing, treatment and reproductive choices.

The Director of the National Human Genome Research Institute in the United States warns us that "all of us carry probably 4 or 5 really fouled up genes and another couple of dozen that are not so great and place us at risk for something" 6 and that "Each of us has between 5 and 30 misspellings or alterations in our DNA; thus, we could all be targets for discrimination based on our genes. Like racism, sexism, and other forms of prejudice, genetic discrimination devalues diversity, squanders potential, and ignores achievement". ${ }^{7}$ The frightening but sometimes forgotten thing is that none of us have control over our 
genetic makeup. It is not our fault in the way that smoking or taking part in at-risk activities clearly is.

The success of genetics in identifying the links with disease and the propensity to disease has led to widespread concern and fear on the part of the general public, scientific committees, government and those who feel themselves to be particularly at risk of a loss of insurability. Given that in the UK many mortgages are tied directly to life insurance, and that there is an increasing market for, and increasing availability of, health insurance and standard life insurance and assurance policies, there is a genuine fear that there will be discrimination and bias against individuals who are, or are perceived to be, at risk of genetically linked disease. This fear operates at two levels. Genetic tests already undertaken or recognised might be misinterpreted or otherwise misused. That there is a predisposition does not allow an accurate prediction about the actual onset, the timing or the severity of a genetically based disease. These are probabilities not certainties. The insurance industry responds to this point by stressing that it deals all the time with possibilities and risk. The industry has experiences of rating such risks and so there need be little fear of abuse.

The other fear is that discriminatory practices will lead to the demand from insurance companies that individuals or families be tested for genetic disease, that the results of such tests or the refusal to take such a test would lead to the denial of coverage, the limitation of coverage or to excessive levels of premiums. And, what is of wider concern, there might arise a situation where an individual decided or was forced to forgo a genetic test which might be highly beneficial. An individual or family might fear that a genetic test and result might indicate the possibility or even probability of a disease developing. It is entirely natural to suppose that any insurance company or would-be employer might refuse insurance or employment, if they were privy to that genetic knowledge. Such a refusal to be tested might prevent knowledge of one's status, treatment and preventive steps, especially in relation to crucial environmental factors which might play a key role in the onset or severity of a genetically linked disease. Such a refusal might also lead, as it seems already to have done in the United States, to insurers denying insurance and accordingly, people refusing to impart genetic or family information. In spite of a legal duty to disclose known, relevant information, people can and do withhold such details. "In a recent survey of people in families with genetic disorders, 22 per cent indicated they, or a member of their family, had been refused health insurance on the basis $\delta$ their genetic information."7

Medical researchers have already found thâ some people are unwilling to take part in research programmes. Dr Barbara Weber and her cot leagues in Pennsylvania are trying to understano breast cancer gene mutations. Nearly one third of high-risk people refuse to take part in the studi because they fear discrimination and loss of privacy. ${ }^{8}$

\section{Motives matter}

It is a truism that moral reflection on action includes a close examination of motives. The way in which HIV testing and results were handled and used to deny insurance altogether or ta require higher premiums has not created confit dence that genetic information gained from testing will be any different. The insurance industry exists to make a profit and benefit is shareholders. It is also easy to accuse insurance companies of self-interest in seeking to avor insuring or paying out insurance when there wefe predisposing factors which could have beer known by genetic testing. The negative pres comment and reporting coupled with concero expressed by various independent and government-sponsored committees has led public concern and fear of discrimination. If w contrast the acceptance of responsibility anel desire to ensure good insurance practice by avoi重 ing the wrong kind of discrimination, then we have a clear choice of motives on the part of insuran companies. No one pretends that commercial concerns and profits are irrelevant, but that is ven. far from suggesting that these are the only or evein overriding, motives. There is inevitably an awareness on the part of the insurance industry that if $\dot{\phi} t$ does not set its own house in order, put in plage good practice and ensure that that is publicly see understood and appreciated, then governmen will introduce legislation, which is likely to 18 much more punitive and restrictive than the insurance industry would wish.

The insurance industry is concerned that hig risk individuals will purchase excessive insurange and that people with a low risk of genetic disease will not see the need for life or health cover. They are concerned that individuals who know that the have a genetically based disease will withhold thot information, thus making a claim more likel raising the premiums for others and, in $q$ nightmare analysis, causing bankruptcy. There ts also a concern that there may be excessive sunfs involved in insuring, when genetic information may be a key factor. 
It is important to distinguish situations where the family history has already indicated possible disease and this is clearly an existing part of an individual's medical record, and a requirement that someone take a genetic test before she is insured. It is hard to see the logic of denying access to medical records on genetic grounds, when these records are already available. It might be that the seriousness of that information is such that it should be withheld, but that seems to undermine the whole process of insurance and consultation of medical records with the consent of the one seeking to be insured. Consent is crucial here, but there will and does arise the scenario where an individual happily gives consent for an insurance or mortgage company to have access to his medical records, not fully realising the significance of those records. Avoiding paternalism and accepting that all of us have to take responsibility for our own mistakes, doctors do have an obligation to make sure that patients understand not only what is written in their medical records, but also the significance of that for patients, especially in terms of employment and insurance.

It is not beyond the wit and ability of insurance underwriters to develop a means whereby everyone can be insured, even if there is a high risk of developing a genetically based disease. It is interesting to note the Norwegian model of a total prohibition on using genetic test information, in contrast to the Netherlands where a "ceiling" approach is legislatively implemented. Some argue that there might be flexibility about the term, ie the length of time covered, and/or the amount of both health and life insurance. It is vital, however, that underwriters be aware of the major limitations of genetic tests and testing.

The actual numbers of people suffering from many of the currently identified genetically linked diseases is relatively small. If we reach a stage where we find that vast numbers are at risk and involved, then not only will our understanding of "normality" have to be adjusted, but the risk base will be so broadened that insurance will become more possible and realistic. The rarity of such diseases must be set alongside the unreliability of tests. There may be false positives and the test itself does not indicate the severity of the disease in any particular case. Indeed, there is no 100 per cent guarantee, in many cases, that the having of the gene will lead to the disease. Monogenic diseases are more rare than multifactorial genetically linked diseases. Thus in serious risk assessment, there are many factors to be used. The danger is that of a very cautious approach on the part of the underwriters. Of key importance here will be the role of the genetics adviser to the insurance industry and the public availability of information about decisions made for insurance purposes, which are dependent on genetic tests. Coupled with these must be a clear, public, independent appeals system, as is envisaged by the ABI.

When it comes to issues of confidentiality, sensitivity in handling personal genetic information, security and the moral values of privacy and respect, then insurance companies are on stronger ground in the sense that they are already well versed in such practices. Like us all, they are subject to the various data protection provisions.

There seems in principle no great difference in keeping information secure in the case of genetics than in any other medical or insurance area. Other medical information may be just as serious.

Where the insurance industry has tried to be proactive is by announcing a moratorium on the requirement and use of genetic tests and in the rejection of setting favourable rates for those who have a "good" genetic profile. It is to be hoped that this will become a permanent fixture, until and unless there are startling new genetic discoveries and adequate societal and political reflection and consideration of how to proceed. The industry has also been proactive in setting in place a code of good practice and appointing an independent review body for breaches and complaints. It is important to have such measures in place, but it is also important that adequate sanctions are linked with any breach of the code within a company or by a company. The nature of the ABI is that it is a voluntary organisation and the degree to which sanctions are possible, is far from clear. The insurance industry must continue to work closely with the medical and political groups who have expertise and concern in, and for, this area of life. But we must not expect the insurance or any other industry to take responsibility for medical research or for health care and protection for the vulnerable. Insurance does not happen in a vacuum and the role of genetics and insurance is part of a wider discussion. The continuing role of the Human Genetics Advisory Commission and in particular its December 1997 report and recommendations will ensure that the insurance industry keeps in step with the wider concerns of relevant bodies. ${ }^{9}$

\section{Ethics, genes and insurance}

It is salutary to contrast the processes in the UK with the developments in the US, where the legislative route has been taken. Of course, there are crucial differences in health care provision, insurance and the legal and political structures and 
operations, nevertheless, the results and recommendations from an Ethical, Legal and Social Implications of Human Genome Research workshop are salutary:

“1. Insurance providers should be prohibited from using genetic information, or an individual's request for genetic services, to deny or limit any coverage or establish eligibility, continuation, enrolment, or contribution requirements.

2. Insurance providers should be prohibited from establishing differential rates or premium payments based on genetic information or an individual's request for genetic services.

3. Insurance providers should be prohibited from requesting or requiring collection or disclosure of genetic information.

4. Insurance providers and other holders of genetic information should be prohibited from releasing genetic information without prior written authorisation of the individual. Written authorisation should be required for each disclosure and include to whom the disclosure would be made."10

Ethics and morality must continue to play an advisory role in helping society to come to terms with the insurance and employment implications of genetics. It is not only too dangerous to leave it to the geneticists and insurers. It is hoped the legislation can be avoided by good practice which retains public support and confidence. The retreat to legislation is a confession of failure in terms $\overrightarrow{\text { off }}$ our ability to relate to each other and to order ow medical and insurance practices. The perforn ance of the insurance industry thus gives son $\overline{\overline{f e}}$ cause for optimism.

E David Cook is Fellow and Chaplain of Green Cö lege, Oxford and Director of the Whitefield Institute:-

\section{References}

1 Nuffield Council on Bioethics Working Party. Genetic screenisur. ethical issues. London: Nuffield Council on Bioethics, 1993 DèO

2 House of Commons Science and Technology Committe Human genetics: the science and its consequences [Third Repory] London: HMSO, Jul, 1995: vol 1, para 247.

3 See Reference 2:248.

4 Association of British Insurers. Policy statement on life assurance and genetics. London: Association of British Insurers, Feb 1997

5 Association of British Insurers. Genetic code of practice. Lond ABI, 1997.

6 Collins FS. Evolution of a vision part II. Human Genome Nezus 1995;7,3:16, published by the US Department of Energ Human Genome Project.

7 Department of Health and Human Services. Health insurance in the age of genetics. Washington, USA: Department of Health afe Human Services, Jul 1997.

8 Kolata G. Advent of testing for breast cancer genes leads to fer of disclosure and discrimination. New York Times 1997 Feb Section C Science Desk:1; Cowley G. Flunk the test and loge your insurance. Newsweek 1996 Dec 23 48-50.

9 Human Genetics Advisory Commission. Implications of gen testing for insurance. London: Department of Health, 1997.

10 Hudson KL et al. Genetic discrimination and health insuran an urgent need for reform. Science 1995; 270:3913.

$$
\text { of genetics. It is not only too dangerous to leave it }
$$

